\title{
Sternal wire removal in pediatric patients: Wire versus cable sternotomy closure
}

\author{
Lester C. Permut, MD, Justin Linam, MA, and Gordon A. Cohen, MD, PhD, Seattle, Wash
}

Secure sternal closure after median sternotomy is important to facilitate sternal healing, optimize ventilatory mechanics, and minimize discomfort in the early postoperative period. Many techniques have been reported for sternal closure in adults, with the most widely used involving permanent stainless steel wires or cables. In the pediatric population, absorbable sutures may be used in smaller patients, but stainless steel wire or cable closure is generally preferred for larger children and teens.

Although uncommon, persistent chest wall pain related to sternal wire closure is well described in the adult population and may necessitate reoperation for wire removal. ${ }^{1-4}$ This finding has not been described after cable closure in adults. Furthermore, the frequency of persistent pain after sternal closure with either wire or cable systems in children is unknown. Beginning in March 2005, a cable system was used for sternal closure in all patients larger than $30 \mathrm{~kg}$ at our institution. A seemingly disproportionate rate of reoperation for cable removal was subsequently observed. We therefore reviewed our institutional experience with wire and cable sternal closures to compare the performances of these sternal closure systems in the pediatric population.

\section{CLINICAL SUMMARY}

We retrospectively reviewed patient medical records and our operative database to gather demographic and follow-up data on all patients larger than $30 \mathrm{~kg}$ who underwent sternal closure with wires or cables from 2002 to 2007 . We received approval from our institutional review board with a waiver of individual consent.

The Pioneer Sternal Cable System (Pioneer Surgical Technology, Inc, Marquette, Mich) was used in 48 patients during a 27-month period from March 2005 to June 2007. Cables were placed in a figure-of-eight parasternal configuration. We compared this cohort with all 75 patients larger than $30 \mathrm{~kg}$ who had undergone sternal closure with wires during the preceding 27 -month period. In the latter group,

\footnotetext{
From the Section of Pediatric Cardiothoracic Surgery, University of Washington School of Medicine, Seattle, Wash

Disclosures: None.

Received for publication March 12, 2009; revisions received June 19, 2009; accepted for publication July 6, 2009; available ahead of print Aug 7, 2009.

Address for reprints: Lester C. Permut, MD, University of Washington School of Medicine, Pediatric Cardiothoracic Surgery, Seattle Childrens Hospital, 4800 Sand Point Way NE, Seattle, WA 98105 (E-mail: lester.permut@seattlechildrens.org).

J Thorac Cardiovasc Surg 2010;139:1663-4

0022-5223/\$36.00

Copyright (c) 2010 by The American Association for Thoracic Surgery

doi:10.1016/j.jtcvs.2009.07.003
}

TABLE 1. Wire and cable subpopulation demographic data

\begin{tabular}{lcc}
\hline & Wire & Cable \\
\hline No. of patients & 75 & 48 \\
Sex $(\%$ male) & $69.3 \%$ & $68.8 \%$ \\
Age $(y$, mean $\pm \mathrm{SD})$ & $14.3 \pm 3.0$ & $15.28 \pm 2.6$ \\
Weight $(\mathrm{kg}$, mean $\pm \mathrm{SD})$ & $56.2 \pm 19.9$ & $60.9 \pm 16.2$ \\
Follow-up $(\mathrm{y}$, mean $\pm \mathrm{SD})$ & $2.5 \pm 1.8$ & $1.5 \pm 1.0$ \\
Reoperation for suture & $0(0.0 \%)$ & $5(10.4 \%)$
\end{tabular}

removal (no.)*

*Difference statistically significant by Fisher exact test $(P=.008)$.

No. 5 stainless steel wires were placed in a simple or figure-of-eight parasternal configuration according to surgeon preference.

Exact binomial confidence intervals and the Fisher exact test were used for statistical comparison of suture removal frequency between the wire and cable cohorts. Data are presented in Table 1. None of the patients in the wire cohort had chest wall pain that necessitated wire removal during the follow-up period (mean proportion, $0.0 \%$; 1 -sided $97.5 \%$ confidence interval, $4.8 \%$ ). Five of the 48 patients in the cable cohort had chest wall pain that necessitated cable removal during the study period (mean proportion, 10.4\%; $95 \%$ confidence interval, $3.5 \%-22.7 \%$ ). The Fisher exact test showed the increased incidence of cable removals to be statistically significant $(P=.008)$. Patients requiring cable removal appeared to be marginally significantly smaller ( $t$ test, $P=.037$ ) but did not differ from the group without cable removal with regard to age or sex (Table 2).

\section{DISCUSSION}

Early or late postoperative discomfort related to stainless steel sutures is estimated to occur in approximately $1 \%$ of adults after median sternotomy. ${ }^{1-4}$ Proposed etiologic mechanisms include hypersensitivity reaction to nickel or iron in the stainless steel alloy. ${ }^{1-3}$ Mechanical factors, such as eversion of the twisted portion of the sternal wires or friction between the wires and tissues, have also been implicated.

TABLE 2. Cable cohort demographic data

\begin{tabular}{lcc}
\hline & Removed & Not removed \\
\hline No. of patients & 5 & 43 \\
Sex $(\%$ male $)$ & $80 \%$ & $60 \%$ \\
Age $(\mathrm{y}$, mean $\pm \mathrm{SD})$ & $16.1 \pm 1.7$ & $15 \pm 2.7$ \\
Weight $(\mathrm{kg}$, mean $\pm \mathrm{SD}) *$ & $53.8 \pm 5.4$ & $61.8 \pm 16.9$ \\
\hline *Difference statistically & significant by & $t$ test accounting for unequal variance \\
$(P=.037)$. &
\end{tabular}


No data have been reported regarding sternal pain in children. The standard treatment for poststernotomy pain or discomfort in both adults and children is removal of the involved sutures.

Sternal closure with the Pioneer Sternal Cable System affords potential advantages, including a flatter anterior profile and greater biomechanical strength than stainless steel wires. ${ }^{5}$ On the basis of reports in the adult population, we began to use the cable system for sternal closure in larger pediatric patients. Despite the potential advantages, we observed a $10.4 \%$ incidence of postoperative discomfort or pain necessitating cable removal relatively early after surgery. In contrast, no patients in a size-matched cohort undergoing sternal closure with wires in the period immediately preceding cable use required suture removal, despite a longer period of follow-up.

The etiology of the greater incidence of pain and discomfort with sternal cables in these pediatric patients is unclear. The stainless steel alloys in the Pioneer Sternal Cable System and the sternal wires used at our center are identical, so hypersensitivity to nickel or iron is unlikely. The grommets used for cable closure may protrude slightly more than wire sutures, although good soft tissue coverage of the sternum was obtained in both groups. Regardless of the cause, cable closure of the sternum in pediatric patients larger than $30 \mathrm{~kg}$ was associated with an unacceptably high incidence of postoperative pain necessitating reoperation for cable removal. Use of cables for sternal closure should be carefully considered in this patient population.

\section{References}

1. Eastridge CE, Mahfood SS, Walker WA, Cole FH Jr. Delayed chest wall pain due to sternal wire sutures. Ann Thorac Surg. 1991;51:56-9.

2. Fine PG, Karwande SV. Sternal wire-induced persistent chest pain: a possible hypersensitivity reaction. Ann Thorac Surg. 1990;49:135-6.

3. Gordon PM, Buxton PK, McLaren KM, Aldridge RD. Sensitivity to sternotomy wires may cause postoperative pruritus. Ann Thorac Surg. 1996;61:1514-6.

4. Nørgaard MA, Andersen TC, Lavrsen MJ, Borgeskov S. The outcome of sternal wire removal on persistent anterior chest wall pain after median sternotomy. Eur J Cardiothorac Surg. 2006;29:920-4.

5. Cohen DJ, Griffen LV. A biomechanical comparison of three sternotomy closure techniques. Ann Thorac Surg. 2002;73:563-8. 